\title{
Eurocentrismo e racismo ou Em torno da periculosidade das teorias
}

\section{Eurocentrism and racism or About the danger of theories}

\author{
Suze Piza $a^{*}$ \\ Daniel Pansarelli $i^{* *}$
}

Recebido: 07/2016

Aprovado: 11/2016

\begin{abstract}
Resumo: Embora a questão do racismo venha sendo problematizada há décadas, especialmente na América Latina e na África, por teóricos de diversas áreas do campo das Ciências Humanas, aparentemente ainda são raros os estudos propriamente filosóficos a este respeito. Nesse artigo partimos de posições pontuais acerca da questão racial, manifestas por diversos pensadores - tomamos o cuidado de selecionar autores a quem podemos considerar, cada um a seu modo, co-responsáveis pela estruturação da sociedade ocidental contemporânea, seja em suas formas de organização dos estados, da justiça, dos sistemas ético-políticos. A partir destes autores, problematizamos um elemento político das teorias filosóficas, destacando que suas construções teóricas pressupõem uma certa concepção - racista, como veremos - de ser humano, a qual se reflete na própria concepção de organização social. Passamos, a seguir, para uma análise de como fenômeno similar pode ser verificado no pensamento hegeliano, o qual é tomado como ponto de partida filosófico por uma variedade dos mais relevantes filósofos deste início de século XXI. Concluímos, então, com uma crítica de perfil pós-colonialista a este padrão teórico, veladamente racista, que se constituiu como corpus filosófico eurocêntrico, influindo ainda hoje na organização social.

Palavras-chave: Eurocentrismo; Racismo; Filosofia; Ciências.
\end{abstract}

\begin{abstract}
Even though the question of racism, in particular in Latin America and Africa, has been rendered problematic for decades by theorists from diverse areas of Human Sciences, philosophical studies on the subject appear to be rare. The following article is based on specific arguments surrounding the issue of racism, as given by various thinkers. We have been careful to choose authors whom we can consider, each in his own way, co-responsible for structuring contemporary western society, whether it be regarding the way that states, the justice system or ethical-political systems are organized. Based on these authors, we analyze a political element of philosophical theories, highlighting that their theoretical constructions assume a certain conception - the racist, as we see it - of the human being, which is reflected in the very conception of social organization. We then analyze how a similar phenomenom can be verified by Hegelianism, a line of thought used as the starting point for a number of the most relevant philosophers since the be beginning of the 21 st century. We thus conclude, with a critical post-colonist profile regarding this theoretical norm - the concealed racist - that it was established as a Eurocentric philosophical corpus, that to this day continues to influence social organization.
\end{abstract}

Keywords: Eurocentrism; Racism; Philosophy; Sciences.

\section{Introdução}

Embora a questão do racismo venha sendo problematizada há décadas, especialmente na América Latina e na África, por teóricos de diversas áreas do

\footnotetext{
Filósofa, doutora em Filosofia pela Unicamp. Professora na Universidade Federal do ABC. E-mail: suze.piza@ufabc.edu.br.

Filósofo, doutor em Educação pela USP. Professor e atual pró-reitor de extensão e cultura na UFABC. Email: pansarelli@gmail.com.
} 
campo das Ciências Humanas, aparentemente ainda são raros os estudos propriamente filosóficos a este respeito. É verdade que há no Brasil importantes grupos que tomam a questão das africanidades e das ancestralidades, os quais procuram oferecer à comunidade acadêmica reflexões que partam de orientações africanas - e não de norteadores eurocêntricos. Nossa intenção neste artigo é somar com estes grupos, trazendo à crítica a relação intrínseca, estabelecida ao longo da Modernidade, entre teorias filosóficas eurocêntricas e a questão racial.

O caminho a ser percorrido é bastante simples. Partimos de posições pontuais acerca da questão racial, manifestas por diversos pensadores tomamos o cuidado de selecionar autores a quem podemos considerar, cada um a seu modo, co-responsáveis pela estruturação da sociedade ocidental contemporânea, seja em suas formas de organização dos estados, da justiça, dos sistemas ético-políticos. A partir destes autores, problematizamos um elemento político das teorias filosóficas, destacando que suas construções teóricas pressupõem uma certa concepção - racista, como veremos - de ser humano, a qual se reflete na própria concepção de organização social. Passamos, a seguir, para uma análise de como fenômeno similar pode ser verificado no pensamento hegeliano, o qual é tomado como ponto de partida filosófico por uma variedade dos mais relevantes filósofos deste início de século XXI. Concluímos, então, com uma crítica de perfil pós-colonialista a este padrão teórico, veladamente racista, que se constituiu como corpus filosófico eurocêntrico, influindo ainda hoje na organização social.

\section{Eurocentrismo, racismo e o espírito de um tempo}

Uma citação de Kant, extraída de seu texto Observações sobre o sentimento do belo e do sublime tem sido usada em vários momentos para denunciar o caráter eurocêntrico dessa Filosofia e em especial da presença de um racismo antinegro.

Kant afirma,

Na minha opinião, entre os povos do nosso continente, os italianos e os franceses são aqueles que se distinguem pelo sentimento do belo; já os alemães, os ingleses e espanhóis, pelo sentimento de sublime [...] O espanhol é sério, reservado e sincero [...] O francês possui um sentimento dominante para o belo moral. É cortês, atencioso e amável [...] No início de qualquer relação o inglês é frio, mantendo-se indiferente a todo estranho. Possui pouca inclinação a pequenas delicadezas; todavia, tão logo é um amigo, se dispõe a grandes favores [...] O alemão no amor, tanto quanto nas outras espécies de gosto, é assaz metódico, e, unindo o belo e o nobre, é suficientemente frio no sentimento de ambos para ocupar a mente com considerações acerca do decoro, do luxo ou daquilo que chama a atenção [...] (KANT, 1993, pág. 65-70) 
Indicando que não está sozinho na reflexão, cita Hume, que pensa o mesmo, e continua:

\begin{abstract}
Os negros da África não possuem, por natureza, nenhum sentimento que se eleve acima do ridículo. O senhor Hume desafia qualquer um a citar um único exemplo em que um Negro tenha mostrado talentos, e afirma: dentre os milhões de pretos que foram deportados de seus países, não obstante muitos deles terem sido postos em liberdade, não se encontrou um único sequer que apresentasse algo grandioso na arte ou na ciência, ou em qualquer outra aptidão; já entre os brancos, constantemente arrojam-se aqueles que, saídos da plebe mais baixa, adquirem no mundo certo prestígio, por força de dons excelentes. Tão essencial é a diferença entre essas duas raças humanas, que parece ser tão grande em relação às capacidades mentais quanto à diferença de cores. A religião do fetiche, tão difundida entre eles, talvez seja uma espécie de idolatria, que se aprofunda tanto no ridículo quanto parece possível à natureza humana. A pluma de um pássaro, o chifre de uma vaca, uma concha, ou qualquer outra coisa ordinária, tão logo seja consagrada por algumas palavras, tornam-se objeto de adoração e invocação nos esconjuros. Os negros são muito vaidosos, mas à sua própria maneira, e tão matraqueadores, que se deve dispersálos a pauladas. (KANT, 1993: pág. 75-76)
\end{abstract}

O texto é forte e pode até envergonhar aqueles que se identificam com a Filosofia de Kant ou ainda levar alguns poucos a se afastarem dessa Filosofia por não querer tal identificação, afinal: como alguém dessa envergadura e reputação filosófica pode dizer algo tão execrável? Contudo diante dessas passagens, a maioria dos estudiosos de Kant diria com tranquilidade: Kant é um homem de seu tempo! Não se pode esperar que alguém do século XVIII, naquele início da modernidade e naquele contexto cultural pensasse de forma diferente... E ainda diriam: Não podemos tratar uma Filosofia dessa forma, tomando um trecho da obra pela obra como um todo.

Dois bons argumentos. Concordamos. De fato, não é possível ignorar o sentido temporal, histórico de uma Filosofia, muito menos deixar de considerar o sentido geográfico de um pensamento como uma espécie de solo em que as ideias são produzidas. Tanto é verdade que os sentidos histórico-geográficos são determinantes para a produção de pensamento que Kant e Hume, citados acima, não estão sozinhos. Vemos em diversos filósofos e teóricos das ciências humanas ideias semelhantes.

Tocqueville em A democracia na América nos brinda com sua reflexão:

O escravo moderno não difere do senhor apenas pela liberdade. Mas ainda pela origem. Pode-se tornar livre o negro, mas não seria possível fazer com que não ficasse em posição de estrangeiro perante o europeu. $E$ isso ainda não é tudo: naquele homem que nasceu na degradação, naquele estrangeiro introduzido entre nós pela servidão, apenas reconhecemos os traços gerais da condição humana. $O$ seu rosto parece-nos horrível, a sua inteligência parece-nos limitada, os seus gostos são vis, pouco nos falta para que o tomemos por um ser intermediário entre o animal e o homem" (TOCQUEVILLE, 1977: pág. 262). 
$\mathrm{Na}$ visão de Tocqueville fica explícita a tese que escravidão não se trata apenas de libertação econômica ou de libertação política, afinal há uma origem nesses homens que não tem como ser negada. O negro sempre será estrangeiro diante do europeu, afinal nele reconhecemos apenas "traços gerais da condição humana". O negro não é humano, assim pensa um dos grandes referenciais da teoria política ocidental. As referências depreciativas aparecem também em Max Weber ${ }^{1}$ quando em uma de suas principais obras $A$ Ética protestante e o espírito do capitalismo afirma que

Além da aparência dos negros puros, que do ponto de vista estético, é muito mais estranha do que a dos índios e certamente constitui um fator de aversão, sem dúvida contribui para esse fenômeno a lembrança de os negros, em oposição aos índios, terem sido um povo de escravos, isto é, um grupo estamentalmente desqualificado" (WEBER, 1991: pág. 268).

Ou ainda Durkheim ${ }^{2}$ que insere uma hierarquia entre as religiões considerando superiores aquelas que "põe[m] em jogo funções mentais mais elevadas, mais ricas em ideias e sentimentos, nelas figuram mais conceitos, menos sensações e imagens" e que defende que nessas a "sistematização é mais engenhosa" (DURKHEIM, 1978: pág. 205-206). No final da introdução de sua obra, Durkheim parece se desculpar por estudar as religiões que considera "primitivas", afirmando que não pretendida "atribuir virtudes particulares às religiões inferiores [... ]. Ao contrário, elas são rudimentares e grosseiras. [...] Mas - diz o autor - a sua própria grosseria as torna instrutiva; pois elas constituem assim experiências cômodas, onde os fatos e suas relações são mais fáceis de perceber" (DURKHEIM, 1978: pág. 210). Em suma, a tese é que "as religiões inferiores são formas caducas de religiosidade, formas caducas de civilização".

"O espírito do tempo" abarca e atravessa as mentes e não é possível deixar de fora dele nem teorias que são usadas normalmente na direção contrária da dominação e opressão, como a Filosofia de Marx. Marx também era um homem de seu tempo, prova disso é seu texto sobre o domínio britânico na Índia.

Árabes, Turcos, Tártaros, Mongóis, que sucessivamente invadiram a Índia, cedo ficaram indianizados, uma vez que, segundo uma lei eterna da história, os conquistadores bárbaros são eles próprios conquistados pela superior civilização dos seus súditos. Os Britânicos foram os primeiros conquistadores superiores e, por conseguinte, inacessíveis à civilização hindu. Destruíram-na, rebentando com as comunidades nativas, arrancando pela raiz a indústria nativa e nivelando tudo o que era grande e elevado na sociedade nativa. As páginas históricas da sua dominação na Índia quase não relatam mais nada para além essa destruição. A obra de regeneração mal transparece através de um montão de ruínas. Apesar disso ela 
começou. (MARX, 1982: pág. 520).

E não poupa palavras:

\begin{abstract}
não podemos esquecer que estas idílicas comunidades aldeãs, por muito inofensivas que possam parecer, foram sempre o sólido alicerce do despotismo oriental, confinara o espírito humano ao quadro mais estreito possível, fazendo dele o instrumento dócil da superstição, escravizando-o sob o peso de regras tradicionais, privando-o de toda a energia histórica (MARX, 1982: pág. 517).
\end{abstract}

Marx denuncia a violência das civilizações da Índia, considerando a vida daquelas populações como "indigna, estagnada e vegetativa", uma "espécie de existência passiva", que "desencadeava forças de destruição selvagens, sem objetivos e sem limites, e tornavam o próprio assassínio um rito religioso no Indostão". E justifica sem problemas, apoiado pelo espírito do seu tempo, e como se fosse um colonialista, a violência do colonialismo Inglês: "quaisquer que possam ter sido os crimes da Inglaterra, ela foi o instrumento inconsciente da história ao provocar essa revolução" (MARX, 1982, pág. 517-518).

Essas citações, longe de serem as únicas representativas desse espírito, dizem o que para nós? O espírito do tempo no qual esses autores foram formados como pessoas é eurocêntrico e racista. Há um modo de produção da vida econômica ${ }^{3}$ de onde esse espírito brota que favorece essa interpretação dos povos negros como sendo criaturas sem alma, animalizados, tomados como coisas.

A segunda parte dos argumentos mais usuais a favor dessas teorias filosóficas é que não podemos tomar fragmentos de um pensamento pelo seu todo. Seria muita falta de rigor, um mau uso dos recursos hermenêuticos mínimos para se produzir um pensamento que por excelência é identificado como uma das mais belas obras da razão humana, proceder dessa forma tão arbitrária.

Novamente, concordamos. Todavia, gostaríamos de fazer algumas ponderações para que esse cuidado seja tomado em todos os âmbitos e por aqueles que produzem pensamento filosófico hoje. As ponderações são em defesa da coerência. Partindo do princípio que não podemos tomar a parte pelo todo, de que maneira é possível dissociar as concepções antropológicas desses teóricos de suas teorias políticas, éticas e sociológicas? Afinal, não estamos falando de autores que pronunciaram discursos racistas apenas em sua vida privada, e cuja produção intelectual versa sobre áreas meramente formais do saber. Estamos falando de teóricos que pensam e escrevem sobre Filosofia Política e Ética ou Sociologia. Nossa primeira ponderação é: não é possível dissociar a concepção antropológica de um autor de sua teoria quando essa trata justamente dos seres humanos. Se a produção desses autores passasse ao 
largo das questões especificamente humanas, poderíamos dizer que eles, como pessoas são eurocêntricos e racistas, mas produziram algo importante para a humanidade e com isso se deprecia com a crítica as pessoas, mas não o produto criado, o que eles produziram. Este não pode ser o caso quando estamos diante de questões da ética, da política, da justiça.

Como dizer que a Antropologia, a Ética, a Política (inclusive a que versa sobre a relação entre os povos, como é o caso de Kant) não foi afetada e não representa o que ele mesmo pensa sobre o homem? Como dizer que a visão de Durkheim sobre a superioridade do homem em relação à mulher não interferiu nas suas teses sobre divisão social do trabalho? Ou ainda, como dissociar a visão que Tocqueville tem dos seres humanos e da escravidão quando cria seu ideal de razão republicana e de cidadania? E para não deixar Marx [e Engels] de fora, o que fazer com um pensamento que dá base para a revolução dos trabalhadores com tantas observações racistas e depreciativas ${ }^{4}$.

Não há como o racismo não interferir na concepção de uma teoria ética ou política, pois ele é justamente a inabilidade ou até recusa das necessidades, direitos e dignidade do outro, do diferente por ser identificado socialmente como parte de um grupo racial distinto, particular ou que pertence a um determinado lugar geográfico. O racismo é justamente a perversão da relação eminentemente ética entre dois humanos, e é o avesso da Ética. Tentar tomar outras partes dessas filosofias ignorando esses pontos não seria cometer o erro hermenêutico tão temido e que compromete nossa capacidade de pensar sobre esses autores? Ignorar essas partes, não é tão grave quanto usar apenas essas partes e ignorar outras?

O argumento que usa a célebre expressão "homens do seu tempo" é pertinente. Inegavelmente pertinente. No entanto, é importante ressaltar que o que eles afirmam não fica no tempo deles, mas chega ao nosso. Esses autores estão no nosso tempo, são nossos contemporâneos na medida que são estudados, esmiuçados, dissecados por pesquisadores, estudiosos e estudantes de Filosofia e de Ciências Humanas em todo o mundo, principalmente entre nós. São autores de algumas das ideias estruturantes da própria noção ocidental de sociedade, de estado, de justiça. E aí entra uma questão bastante delicada que justamente nos coloca diante de uma aporia: essas teorias são ensinadas em seu todo? Ou essas breves citações chocariam hoje pela sua gravidade até estudiosos desses pensamentos que foram pegos de surpresa com a postura nada ética de seus autores? Os jovens estudantes de Filosofia, quando se encantam com as teorias que estudam, têm conhecimento do posicionamento ético, racial, de seus filósofos?

Como afirma Edward Said,

os filósofos podem conduzir suas discussões sobre Locke, Hume e o empirismo sem 


\begin{abstract}
jamais levar em consideração o fato de que há uma conexão explícita, nesses escritores clássicos, entre suas doutrinas "filosóficas" e a teoria racial, as justificações da escravidão e a defesa da exploração colonial (SAID, 1990: pág. 25).

$[\ldots]$

muitos humanistas de profissão são, em virtude disso, incapazes de estabelecer a conexão entre, de um lado, a longa e sórdida crueldade de práticas como a escravidão, a opressão racial e colonialista, o domínio imperial e, de outro, a poesia, a ficção e a filosofia da sociedade que adota tais práticas (SAID, 1995: p. 14).
\end{abstract}

Se não é prudente e nem honesto tomar a parte pelo todo, o que estamos fazendo todos os dias quando ensinamos aos estudantes as partes das teorias que queremos e publicamos nossos artigos com as mesmas partes que reforçam e dão a impressão que o todo da Filosofia é algo, quando parte significativa, como essas citadas acima, não são consideradas? E ainda, como podemos continuar insistindo na pretensão universalista das Filosofias se o argumento básico para livrar nossos autores de suas concepções indesejáveis (para alguns) é que eles são "homens de seu tempo"? Estamos afirmando com tranquilidade que parte da teoria é universal e a outra parte é contextualizada na cultura, história e tempo, visões de homens.... Inconscientemente, esperamos, parece que estamos adotando um estilo de hermenêutica religiosa, de tido dogmático, em que a escolha daquilo que é literal ou metafórico é feita de acordo com a fé do leitor: crer para compreender.

O que defendemos aqui é que o racismo é parte de uma antropologia, visão de mundo antropológica. Vale lembrar uma das maiores contribuições da Filosofia de Foucault quando faz sua chamada ontologia do presente. Foucault se propõe a fazer Filosofia dentro da tradição crítica, e intenta fazer uma espécie de crítica da razão antropológica nos moldes formais da crítica da razão pura de Kant. Já em As Palavras e as coisas ${ }^{5}$ denuncia que Kant teria nos despertado do sono dogmático e ele, ou o kantismo, não importa aqui, nos adormecido no sono antropológico. A crítica da razão antropológica era tarefa necessária para Foucault (e estamos falando dos anos 60 - século XX), pois, segundo o filósofo francês, o Ocidente estava (está) dormindo um sono tão dogmático quanto o anterior. Se Foucault está correto, a gênese das Ciências Humanas e por que não da Filosofia Moderna desde o século XVIII está atrelada a uma quimera: o homem inventado pelo discurso da epistémê moderna. Essa tese é bastante produtiva para nos ajudar na problemática que estamos apresentando aqui: não é possível dissociar as teorias produzidas pela Filosofia e pelas Ciências Humanas do seu objeto - o homem, ou ainda, se quisermos, o sujeito moderno. Tudo aquilo que nossos autores de referência pensam sobre o homem importa e muito, afinal é sobre exatamente esse homem que eles estão pensando quando criam suas teorias éticas, políticas ou sociológicas.

Se em um exercício hermenêutico (do tipo que temos feito na produção 
de pensamento filosófico quando trazemos diversas e diversas vezes alguns autores e suas ideias como repertório conceitual necessário) tomássemos o seguinte trecho da obra Tratado de Metafísica de Voltaire como referência para sistematizar seu pensamento, qual seria o resultado?

\begin{abstract}
Descendo sobre este montículo de lama e não tendo maiores noções a respeito do homem, como este não tem a respeito dos habitantes de Marte ou de Júpiter, desembarco às margens do oceano, no país da Cafraria, e começo a procurar um homem. Vejo macacos, elefantes e negros. Todos parecem ter algum lampejo de uma razão imperfeita. Uns e outros possuem uma linguagem que não compreendo e todas as suas ações parecem igualmente relacionar-se com um certo fim. Se julgasse as coisas pelo primeiro efeito que me causam, inclinar-me-ia a crer, inicialmente, que de todos esses seres o elefante é o animal racional. Contudo, para nada decidir levianamente, tomo filhotes dessas várias bestas. Examino um filhote de negro de seis meses, um elefantezinho, um macaquinho, um leãozinho, um cachorrinho. Vejo, sem poder duvidar, que esses jovens animais possuem incomparavelmente mais força e destreza, mais ideias, mais paixões, mais memória do que o negrinho e que exprimem muito mais sensivelmente todos os seus desejos do que ele. Entretanto, ao cabo de certo tempo, o negrinho possui tantas ideias quanto todos eles. Chego mesmo a perceber que os animais negros possuem entre si uma linguagem bem mais articulada e variada do que a dos outros animais. Tive tempo de aprender tal linguagem e, enfim, de tanto observar o pequeno grau de superioridade que a longo prazo apresentam em relação aos macacos e aos elefantes, arrisco-me a julgar que efetivamente ali está o homem. $E$ forneço a mim mesmo esta definição: $O$ homem é um animal preto que possui lã sobre a cabeça, caminha sobre duas patas, é quase tão destro quanto um símio, é menos forte do que outros animais de seu tamanho, provido de um pouco mais de ideias do que eles e dotado de maior facilidade de expressão. Ademais, está submetido igualmente às mesmas necessidades que os outros, nascendo, vivendo e morrendo exatamente como eles (VOLTAIRE, 1984, p.62).
\end{abstract}

Um exemplo como esse indica que há vários problemas aí que envolvem a questionável defesa da universalidade das teorias, a interpretação das mesmas teorias não pode desconsiderar justamente o espírito do tempo. Esses autores só poderiam ser perdoados pelos seus dizeres se o que eles disseram estivesse apenas na nossa memória como um pensamento do passado que não nos diz respeito mais. Infelizmente, não é o que ocorre. O problema do que eles disseram, que provavelmente deveria pertencer àquele tempo, faz parte intensa e extensa do nosso tempo, quando seus representantes e propagadores estão entre nós, quando suas teorias são cobradas nas provas aplicadas em nossas escolas, nas nossas livrarias, nas nossas revistas acadêmicas, nas teses de doutorado produzidas, no investimento do dinheiro público nessas pesquisas, e, até muitas vezes, chamados como fundamento para projetos educacionais contra deformações éticas nas nossas instituições. Esses teóricos e suas ideias não estão no passado, eles constroem todos os dias o espírito do nosso tempo ${ }^{6}$. 


\section{Hegel réu}

De todas as marcas do eurocentrismo e racismo na História da Filosofia talvez as mais conhecidas sejam as de Hegel. Deixamos este autor de fora de nossa argumentação inicial propositadamente, para tratar dessa Filosofia e seu impacto entre nós separadamente. Uma pergunta que tem trazido inquietação para aqueles que problematizam a produção de pensamento filosófico e sua razão de ser: por quê Hegel se faz presente de novo entre nós? Estamos nos últimos anos vendo um processo de ressureição ${ }^{7}$ admirável dessa Filosofia que é digna de nota: Lacan ${ }^{8}$, Zizek, Sloterdijk, Honneth, para citar alguns, são teóricos com grande impacto no meio acadêmico e que reavivam Hegel.

Consideramos todas as teorias desses autores geniais, cada uma à sua maneira apresenta uma sagacidade que impressiona pelo poder de análise, e estamos falando de teóricos tanto "de esquerda" quanto "de direita". Mas, nossa questão é: eles realmente precisavam ter trazido Hegel de volta em um movimento de eterno retorno do mesmo? E ainda, é prudente e honesto trazer um pedaço de Hegel e deixar o Hegel que não interessa de fora?

Hegel tem um impacto seríssimo na formação do eurocentrismo e racismo que respiramos no nosso dia a dia. Ele aparece de muitos modos e para muitos fins: é usado pela direita, pela esquerda, pelos republicanistas, seja como inspiração para empreender filosoficamente grandes projetos de investigação ${ }^{9}$, seja como método ${ }^{10}$ seja como teoria antropológico-ético-ontológica com as teses sobre o reconhecimento ${ }^{11}$. Hegel é usado e sua teoria manipulada aos pedaços e usada para vários fins. Não somos contra o manejo das teorias, melhor manejar as teorias que as repetir. Também não é nossa intenção aqui debater o hegelianismo desses autores, afinal, todos temos nossas origens teóricas, referenciais, e a relação com a tradição é uma dimensão importante da existência humana. O problema que nos toca é a falta de coerência existente ao dizermos que não devemos dar atenção ao racismo e ao eurocentrismo desses autores, como se isso não importasse e não fizesse parte deles; e, ainda, como se, ao adotá-los, também não passasse a fazer parte de nós.

Gostaríamos de chamar a atenção, a título de exemplificação, para um desses casos. Alex Honneth em A luta pelo reconhecimento - a gramática moral dos conflitos sociais tem como base de sustentação para sua teoria do reconhecimento, teorias de Hegel. Após longa apresentação de Hegel, principalmente do Sistema da eticidade, Honneth afirma que essa deve ser base para uma teoria do reconhecimento contemporânea ${ }^{12}$ e para nos ajudar a compreender a dimensão moral dos conflitos sociais. Honneth apresenta sua própria teoria como uma atualização das intuições de Hegel quando esse ensaia sua teoria do reconhecimento. A teoria tem boa repercussão no meio acadêmico 
e Honneth já figura como referência para se pensar Ética, inclusive usado para a interpretação de fenômenos políticos recentes no Brasil. A teoria nos parece bastante pertinente e parece dar conta mesmo de muitas facetas da sociedade liberal contemporânea, Honneth defende que uma vida humana digna depende de algumas condições tais como: amor, direitos e solidariedade. No entanto, há algumas questões que queremos levantar: o que Hegel faz aí? Qual Hegel é base dessa teoria?

Naturalmente não é o Hegel que afirma

\begin{abstract}
a principal característica dos negros é que sua consciência ainda não atingiu a intuição de qualquer objetividade fixa, como Deus, como leis, pelas quais o homem se encontraria com a própria vontade, e onde ele teria uma idéia geral de sua essência [...] O negro representa, como já foi dito o homem natural, selvagem e indomável. Devemos nos livrar de toda reverência, de toda moralidade e de tudo o que chamamos sentimento, para realmente compreendê-lo. Neles, nada evoca a ideia do caráter humano [...] A carência de valor dos homens chega a ser inacreditável. A tirania não é considerada uma injustiça, e comer carne humana é considerado algo comum e permitido [...] Entre os negros, os sentimentos morais são totalmente fracos - ou, para ser mais exato inexistentes. (HEGEL, 1999, pág. 83-86. Grifo nosso).
\end{abstract}

Afinal, uma passagem como essa não poderia dar sustentação para pensarmos conflitos sociais e luta recíproca por reconhecimento que tivesse por base o amor, os direitos e a solidariedade.

Poderiam argumentar os defensores do filósofo alemão: não se pode tomar a parte pelo todo, ou ainda se apegar em aspectos circunstanciais da obra e deixar de perceber a grandiosidade do método de Hegel, a dialética. Algumas teorias são apenas teses histórico-culturais ou reflexo de suas visões de antropologia e raça. Suponhamos que concordássemos com isso, mas ainda assim colocássemos a dialética e o próprio Hegel sob suspeita, como réus, e fizéssemos a seguinte pergunta: até que ponto um método é isento da visão de mundo em que foi forjado? A dialética não está entrelaçada na visão de mundo de Hegel, é neutra? De antemão, respondemos - a dialética está totalmente atrelada, ela é na forma método a própria visão de Hegel sobre o mundo, incluindo o eurocentrismo.

$\mathrm{Na}$ Fenomenologia do Espírito, seção A, capítulo IV, intitulado Independência e dependência da consciência de si - dominação e escravidão a dialética é explicitada de maneira admirável ${ }^{13}$. O movimento do reconhecimento - que é movimento mesmo da constituição do Espírito ou da consciência iniciadora do processo de desenvolvimento na fenomenologia do Espírito - se dá pela supressão do outro em uma luta de vida e de morte com vencedor pré-determinado. Na defesa de Hegel diz-se que essa tese não é histórica: o senhor e o escravo são apenas alegorias. O argumento seria válido 
se outros textos que reforçam a defesa do senhor [histórico] se constituindo pela supressão e uso do outro, o escravo [histórico], não existissem. Não é o caso.

Em linhas gerais, Hegel afirma [nesse texto] que a) a consciência de si só em si e para si a partir da legitimação de outra consciência; b) frente a consciência de si há uma outra consciência de si que parece ter vindo de fora; c) na verdade, a outra consciência está dentro da mesma (Hegel afirma que ela suprimiu a outra, pois não a vê como essência); d) esse movimento de reconhecimento é representado pelo agir de uma delas; e) como cada uma delas precisa do reconhecimento da outra, o corolário é o conflito entre elas: uma reconhece a outra é reconhecida; f) a consciência de si, assegura Hegel, é igual a si mesma mediante a exclusão do outro, já que o outro não lhe é essencial como objeto.

Esses passos descrevem a dialética - afirmação, negação e negação da negação - a partir do movimento do reconhecimento. É possível a partir do restante desse texto encontrar afirmações mais contundentes a favor da nossa argumentação, e é possível também isolar esses elementos em um método puro que inclusive pode ser usado às avessas para a libertação ou emancipação dos povos. Sabemos disso. Mas, novamente queremos chamar a atenção para os textos negligenciados e verificar se com eles esse processo de manipulação isenta o próprio método do espírito do seu tempo; depois de ser confrontado com a Filosofia da História de Hegel é possível a alegação de que senhor e escravo são só alegorias - recursos heurísticos?

Vejamos:

Sobre a América e seu grau de civilização, especialmente no México e Peru, nós temos informação, porém isto em nada mais importa haja vista esta cultura ser inteiramente nacional, devendo desaparecer tão logo o Espírito aproxime-se dela. A América sempre se mostrou fisicamente e espiritualmente impotente, e ainda se apresenta assim.

$[\ldots]$

O caráter peculiar do africano é difícil de compreender, pela absoluta razão que em relação a ele nós devemos desistir do princípio que naturalmente acompanha todas as nossas ideias - a categoria de Universalidade.

[...]

Neste ponto nós deixamos a África, para não a mencionar de novo. Pois não é parte histórica do mundo; não tem movimento ou desenvolvimento para exibir. $O$ movimento histórico em si - aquele em sua região nordeste - pertence ao mundo asiático e europeu [...]. O que nós propriamente entendemos por África é o Não Histórico, Não Desenvolvido Espírito, ainda envolvido na condição de mera natureza, e que foi apresentado aqui somente como a soleira da História mundial.

Os trechos de Hegel que citamos acima foram deixados de lado pelos intelectuais contemporâneos antes mencionados, como se isso absolutamente não importasse: afinal, vistos como fragmento de um homem, dentro do espírito 
de seu tempo, esses trechos não comprometeriam a "universalidade", nem ao menos a atualidade ${ }^{14}$ desse pensamento, o que justificaria sua presença no nosso tempo.

Enrique Dussel, em 1492 - O encobrimento do outro: mito da modernidade, já demonstrou suficientemente a gênese do eurocentrismo nesse tipo de teoria, hegeliana. Mas, mais importante aqui, demonstrou que a dialética não pode ser compreendida no campo da lógica ou metodológica, haja visto que ela é ontológica e política. Dussel defende desde os anos 60 do século passado: é necessário que seja implantada uma metodologia de superação desse método dialético. A consciência de si europeia não se relaciona com esse outro [que somos nós], quando se relaciona é dialeticamente, o que garante a supressão do outro assim que a consciência dominadora obtém o reconhecimento (não psicológico, mas sim econômico).

Já nas leituras de Feuerbach, Dussel identificava a crítica à falsa dialética - o que o colocou em movimento na busca por outra, mais verdadeira. O que havia de falso, na dialética hegeliana: tratava-se do processo estabelecido entre o ser e o negado-a-ser, este que só encontra existência no ser daquele. $O$ diálogo, portanto, nunca pode se dar entre duas afirmações, mas tão-só entre uma afirmação e uma negação, a qual só pode se colocar por meio da afirmação que lhe conferiu a primeira. Em termos mais dusselianos, é um diálogo entre o ser e o significado que o próprio ser atribui ao outro. É, portanto, comunicação restrita entre o ser e o próprio ser, mais próximo de uma monalética, se quisermos nomear o método $\mathrm{c}$ om algum rigor ${ }^{15}$.

Mas o fato que ora nos interessa é o seguinte: a ausência de uma crítica teórica ao método (falsamente) dialético permite que ele permaneça como método inquestionado. Seguindo este método - este meio, este caminho - tomase como pressuposto seus próprios fundamentos teóricos, inclusive aqueles indesejáveis, tais como os que recusam qualquer reconhecimento à radical alteridade, ou que reavivam princípios racistas, por exemplo. Ao não se questionar criticamente o método, se escolhe o caminho e, portanto, se limita o horizonte de destinos possíveis ao trabalho de produção filosófica. Sob perspectiva ético-política, se mantém calados os outros, se mantém excluídos os distintos, se mantém alienada a alteridade, sem que estas privações apareçam. Se não se nega o direito de falar, nega-se o valor da palavra dita, a forma propriamente outra do discurso. Assim como Sócrates, em seu julgamento $^{16}$, fora obrigado a se defender em um idioma que lhe era estrangeiro, ao outro não se permite dizer sua própria palavra, conforme seu ethos. Se agride, num discurso de aparente acolhimento. Mas não se acolhe ao outro, e sim a imagem do outro feita pelo mesmo.

Ao lado da dusseliana, outras críticas decolonialistas poderiam ser 
levantadas, todas apontando para a mesma direção: a Filosofia de Hegel precisa ser colocada em um tribunal, precisa ser julgada em sua condição de ápice da Modernidade, ou de base da contemporaneidade - em ambos os casos, eurocêntrica. É isso o que pede a própria razão moderna: suspeitar de si. E os autores que insistem em afirmar Hegel em vez de negá-lo, talvez precisem passar pelo processo de constituição da autonomia (é isso também que pede a razão moderna), pois parecem acreditar que sem esses autores de referência estariam perdidos e sem possibilidade de pensar. Em suma, uma teoria ética, em nosso tempo, já não pode ter como sustentação pensamentos tão carregados de preconceitos.

\section{Considerações finais: pensamento pós-colonial, afro perspectivismo e epistemologias do sul}

Os temas étnico-raciais têm lugar garantido em muitos estudos nas áreas de Antropologia, Ciência Política, Economia, História e até mesmo nas chamadas Ciências sociais aplicadas, mas ainda muito raramente essas investigações integram a Filosofia. A inserção e ampliação dessas temáticas no âmbito da Filosofia é extremamente necessária e isso deve ser feito, a nosso ver, dentro dos departamentos de Filosofia no Brasil. Estes deveriam, além de possibilitar uma contribuição filosófica nesse âmbito, oferecer fundamento teórico-filosófico para as mais diversas ciências quando investigam esse tema. Isso possibilitaria, além de contribuir para pensar temas fundamentais em nosso tempo, que a própria Filosofia se reavivasse com novos ares, novas formas de pensar (tão necessárias à sua própria produção) e atuar em prol da modificação das relações étnico-raciais na sociedade brasileira.

As teorias do pensamento pós-colonial (descolonizador) partem do princípio que não há um sujeito universal e questionam a pseudoneutralidade que essa figura carrega atrelada a si, desfazem a noção de que o discurso filosófico brota de uma racionalidade universal e denunciam que as teorias antropológicas eurocêntricas se referem a um homem ${ }^{17}$ ocidental, branco, civilizado, adulto e heterossexual, culturalmente cristão (NOGUERA, 2014, p.23). Questionam também a noção espacial, da Europa como centro, e derrubam geopolíticas estabelecidas, rechaçam cartografias e combatem os enquadramentos, rotulações e hierarquizações. Sobre a Filosofia acadêmica afirma-se: é uma atividade intelectual atravessada pelo racismo epistêmico e, por conseguinte, pelo epistemicídio, pois ela se funda em uma razão colonial.

É preciso fazer uma crítica dessa razão colonial, não apenas para indicar os freios para que ela se mantenha em limites seguros, mas antes para eliminá- 
la. Aliás, eis um bom uso da herança que nos deixou Kant: lutar contra uma racionalidade que nos leva à cegueira e impede a produção de conhecimento. A denúncia da ideologia da colonização e da própria lógica colonial faz parte desse processo. A epistemologia moderna eliminou de suas reflexões o contexto cultural e político da produção e reprodução do conhecimento. É como se esses temas não fossem questões, ou não merecessem problematização e resolução. O resultado dessa não atenção é uma espécie de ofuscamento que impede o próprio conhecimento de se concretizar. Estamos dependentes de uma epistemologia dominante que, sendo dominante, apresenta-se universal e neutra. A dominação colonial e capitalista global é, também, uma dominação epistemológica que coloca os dominados numa relação de subalternidade.

O domínio epistemológico é baseado na razão colonial. A razão, nessa perspectiva soberana, totalitária, tornou-se, no Ocidente, a racionalidade científica que, como matriz totalitária, recusa o caráter racional de todas as outras formas de saber que não tiverem como critério os princípios epistemológicos e regras metodológicas da epistemologia dominante. Isso nos leva a crer que os processos de descolonização que se iniciaram, historicamente, como um processo de libertação das colônias e formação de Estados-nações independentes, hoje, devem prosseguir com a libertação de uma colonização epistêmica que, se concretizada, abriria espaço para essa visão ${ }^{18}$.

O conhecimento na modernidade foi construído com base na relação entre sujeito e objeto. Essa separação entre quem pensa e o que será pensado ultrapassa os limites da epistemologia, e permite atribuição de sentido também para a antropologia, para a ética e para a política. Os pressupostos, para a instauração dessa relação foram criados pela Europa moderna. A questão que deve ser colocada para investigar essa relação basilar é: quem, ou o que, ocupa a posição do objeto e quais as implicações éticas desse posicionamento? As culturas periféricas à Europa foram isoladas, sem interferência na produção dessa relação e absolutamente sem interferência de outras culturas periféricas que possibilitasse a criação de outras relações que fundamentassem o conhecimento. Além disso, a Europa coloca-se como fundadora e possuidora da modernidade e, portanto, assumindo a posição de sujeito delegando aos outros sujeitos a posição de objeto. É necessário se perguntar sobre que encadeamento de circunstâncias conduziu a que, precisamente no solo do Ocidente e só aqui, se produzissem fenômenos culturais que fossem considerados universais ou ainda que estabelecessem uma hierarquia entre os humanos.

É importante lembrar que essa visão de humanos que temos foi construída recentemente e é tarefa da Filosofia desvelar sua gênese. É sabido que as ciências humanas e a própria Filosofia que as antecedem são forjadas 
em um solo antropológico muito peculiar. O sujeito moderno inventado no século XVIII como aquele que se conhece e que é conhecido será o sujeito e o objeto dessas ciências. Michel Foucault em As palavras e as coisas alerta que apesar de Kant ter-nos oferecido a possibilidade de acordarmos do sono dogmático da metafísica, a própria filosofia kantiana criou um novo sono, o sono antropológico. Kant inventa naquele momento um sujeito que será cuidado e cultivado nos últimos séculos e está aí como ideia entre nós. Se Foucault está certo e está na própria Filosofia de Kant o nascimento do homem tal como o conhecemos, talvez devêssemos, antes de afirmar o universalismo dessa figura humana, lembrar das palavras proferidas por Kant acerca das diferentes raças, sua caracterização e classificação, e a infinidade de adjetivos pejorativos que encontramos nessa e em outras grandes Filosofias.

É inegável o caráter racista e eurocêntrico da Filosofia ocidental, restanos agora perceber que a imagem do sujeito universal é indissociável desse discurso. Resta-nos também inserir na nossa tradição exegética de compilação e releitura dos clássicos da Filosofia uma revisão que considere esse aspecto para a intepretação dessa tradição.

\section{Referências}

BHABHA, Homi K. O local da cultura. Belo Horizonte, Editora UFMG, 1998.

DUSSEL, E. 1492: El encobrimiente del Otro. Hacia el origen del "mito de la Modernidad". La Paz: Plural Editores, 1994.

DUSSEL, E. Método para una filosofía de la liberación: superación analéctica de la dialéctica hegeliana. Salamanca: Ediciones Sígueme, 1974.

DURKHEIM, Émile. Da divisão do trabalho social/As formas elementares da vida religiosa. In: Coleção Os pensadores. São Paulo, Abril Cultural, 1978.

FANON, Frantz. Racisme et culture: Présence Africaine, 2éme série, nos VIII-IXX, juin-nov. 1956, pp. 122-131. . 1971 [1952]. Peau Noire, Masques Blancs. Paris: Éditions du Seuil.

Brasileira. 1979. Os Condenados da Terra. Rio de Janeiro: Civilização

HEGEL, G.W. Friedrich. Filosofia da História. Brasília, Editora da UnB, 1999.

KANT, Emmanuel. Observações sobre o sentimento do belo e do sublime. Campinas, Papirus, 1993.

MARX, Karl. "A dominação britânica na Índia". / "Resultados futuros da dominação britânica na Índia”. In: MARX \& ENGELS. Obras escolhidas. Tomo I. Lisboa, Edições Avante! / Moscou, Edições Progresso, 1982.

MIGNOLO, Walter. "Os esplendores e as misérias da "ciência": colonialidade, 
geopolítica do conhecimento e pluri-versalidade epistêmica”. In: SANTOS, Boaventura de Sousa (org). Conhecimento prudente para uma vida decente: um discurso sobre as ciências revisitado. São Paulo, Cortez, 2004.

MUNANGA, Kabengele. Rediscutindo a mestiçagem no Brasil. Petrópolis, Vozes, 1999.

NOGUERA, Renato. O ensino de Filosofia e a lei 10639. Rio de Janeiro: Palas, 2014.

PIZA, Suze; PANSARELLI, Daniel. Sobre a descolonização do pensamento - a invenção de outras epistemologias. Estudos de Religião, v. 26, n. 43. São Bernardo do Campo: UMESP, 2012.

PLATÃO. Apologie de Socrate. 3.ed. Paris: Flammarion, 2005.

SAID, Edward W. Cultura e imperialismo. São Paulo, Companhia das Letras, 1995.

- Orientalismo: o oriente como invenção do ocidente. São Paulo, Companhia das Letras, 2002.

SANTOS, Boaventura de Sousa (org). Conhecimento prudente para uma vida decente: um discurso sobre as ciências revisitado. São Paulo, Cortez, 2004.

. Para além do pensamento abissal: das linhas globais a uma ecologia dos saberes. In: SANTOS, B. de S.; MENESES, M. P. Epistemologias do sul. São Paulo: Cortez, 2010.

PRAXEDES. Eurocentrismo e racismo nos clássicos da Filosofia. São Paulo: Revista Espaço acadêmico, 2008.

PANSARELLI, D. PIZA, S. Sobre a descolonização do conhecimento. Estudos de religião, 2012, vol. 45 .

TOCQUEVILLE, Alexis. A democracia na América. Belo Horizonte, Editora Itatiaia / São Paulo, Editora da USP, 1977.

WEBER, Max. Economia e sociedade. Vol 1. Brasília, Editora da UnB, 1991.

VOLTAIRE. Tratado de metafísica. Coleção Os pensadores. São Paulo: Abril, 1984.

\footnotetext{
${ }_{2}^{1}$ Autor incontornável nos estudos das Ciências Sociais.

2 Apesar do pensamento eurocêntrico não ser exclusividade da Filosofia, concordamos com Charles Mills (1999, p. 13) quando diz que a Filosofia é a mais branca dentre todas as áreas no campo das Humanidades.

${ }^{3}$ A colonialidade é imposta como parte do projeto capitalista como um padrão de funcionamento mundial e opera, dentre outras coisas, com uma classificação étnico-racial da população de todo o mundo.

${ }^{4}$ Há várias observações em relação a anexação do México aos EUA, na mesma linha do domínio britânico na Índia, com destaque a visão que tanto Marx quanto Engels tem dos mexicanos.

${ }^{5}$ E tantas outras obras como Arqueologia do saber, Introdução à Antropologia de Kant.

${ }^{6}$ Sabemos que muitas são as condições de possibilidade para a existência do racismo e não é nossa intenção culpabilizar especialmente os filósofos por isso. Não faz parte do escopo desse
} 
artigo oferecer uma teoria da gênese do racismo, e nem ao menos confrontar as diversas visões acerca das origens do racismo antinegro. Nosso intuito é chamar a atenção para a responsabilidade compartilhada do meio filosófico, e, portanto, nossa também, para essa questão.

${ }^{7}$ Não que sua morte tenha ocorrido de fato, mas parece ter desmaiado ou adormecido por algum tempo.

${ }^{8}$ Que nos últimos anos ganha no Brasil um espaço que não tinha nas últimas décadas, e cujas teorias não se limitam a clínica, mas tem sido base para a interpretação da política.

${ }^{9}$ Como Sloterdijk em Esferas fazendo sua fenomenologia e descrição do movimento do real.

${ }^{10}$ Como fazem os marxistas.

${ }^{11}$ Como fizeram Lacan, Zizek e Honneth.

${ }^{12}$ Negligenciando inclusive Marx, Sorel e Sartre, os quais o autor (des)qualifica como perversões de Hegel.

${ }_{13}$ Importante ressaltar que esse Hegel não interessou a Honneth, que sequer coloca a Fenomenologia do espírito entre as obras de base da sua argumentação. Provavelmente percebeu que esse Hegel não Ihe servia.

${ }_{14}$ Interessante como é flexível o critério para considerar que um filósofo é atual.

${ }^{15}$ Como superação desta falsa dialética, Dussel propõe o método analético, ou ana-dia-lético. Ver em especial o quinto capítulo de sua obra Método para uma filosofia da libertação.

${ }^{16}$ Apologia de Sócrates, 17a-19a.

${ }_{17}^{17}$ Homem não como equivalente a humano, mas a humano do sexo masculino.

18 Sobre este assunto, ver nosso artigo Sobre a descolonização do pensamento (PIZA, PANSARELLI, 2012). 